\title{
SLOW CRACK GROWTH ANALYSIS OF ADVANCED STRUCTURAL CERAMICS UNDER COMBINED LOADING CONDITIONS - DAMAGE ASSESSMENT IN LIFE PREDICTION TESTING
}

\author{
Sung R. Choi* \\ Ohio Aerospace Institute, Cleveland, Ohio 44142, USA \\ [Sung.R.Choi@grc.nasa.gov] \\ John P. Gyekenyesi \\ NASA Glenn Research Center, Cleveland, Ohio 44135, USA \\ [John.P.Gyekenyesi@grc.nasa.gov]
}

\begin{abstract}
Slow crack growth analysis was performed with three different loading histories including constant stress-rate/constant stress-rate testing (Case I loading), constant stress/constant stress-rate testing (Case II loading), and cyclic stress/constant stress-rate testing (Case III loading). Strength degradation due to slow crack growth and/or damage accumulation was determined numerically as a function of percentage of interruption time between the two loading sequences for a given loading history. The numerical solutions were examined with the experimental data determined at elevated temperatures using four different advanced ceramic materials, two silicon nitrides, one silicon carbide and one alumina for the Case I loading history, and alumina for the Case II loading history. The numerical solutions were in reasonable agreement with the experimental data, indicating that notwithstanding some degree of creep deformation presented for some test materials slow crack growth was a governing mechanism associated with failure for all the test materials.
\end{abstract}

\section{INTRODUCTION}

Advanced ceramics are candidate materials for high-temperature structural applications in heat engines and heat recovery systems. One of the mayor limitations of these materials in high temperature applications is delayed failure, where slow crack growth (also called 'fatigue' or 'subcritical crack growth') of inherent flaws can occur until a critical size for catastrophic failure is attained. Therefore, it is important to evaluate accurately slow crack growth (SCG) behavior with a specified loading condition so that reasonable life prediction of ceramic components is ensured.

There are several methods of determining SCG of advanced ceramics. Typically, the SCG of ceramics is determined by applying constant stress-rate (also called "dynamic fatigue"), constant stress (also called "static fatigue" or "stress rupture") or cyclic stress (also called "cyclic fatigue") to ground specimens or to precracked fracture mechanics specimens in which the crack velocity measurements are made. Constant stress-rate testing determines the strength for a given applied stress; whereas, constant stress and cyclic stress testing measures time to failure for given constant stress and cyclic stresses, respectively. Of these test methods, constant stress-rate testing has been widely utilized for decades to characterize SCG behavior of ceramic materials at both ambient and elevated temperatures. The advantage of constant stress-rate testing over other methods lies in its simplicity: Strengths are measured in a routine manner at four to five applied stress rates by applying either displacement-control mode or load-control mode. The SCG parameters for life-prediction/design are simply calculated from a relationship between strength and applied stress rate. Because of its advantages, constant stress rate testing has been developed as an ASTM test standard (C1368-97) to determine SCG parameters of advanced ceramics at ambient temperature [1]. The advantages of constant stress-rate testing have also promoted an effort to develop a companion test standard to evaluate SCG parameters at elevated temperatures, which is under consideration within ASTM C28 Advanced Ceramics Committee [2].

One of the difficulties possibly encountered in elevated-temperature testing is that, depending on test conditions (test rate, time, temperature and environment) and material, the identification of a goveming failure mechanism may be obscured by the presence of possible multiple mechanisms, particularly with a combination of SCG and creep [3-6]. Thus, the determined SCG parameters cannot be solely representative of one single process, slow crack growth, but a combination of the two competing mechanisms. They may also act in series, i.e., creep followed by SCG. The underlying basis of the aforementioned SCG testing - constant stress-rate, constant stress and cyclic stress testing - is the crack velocity formulation in which crack propagation typically follows a power-law relation. If the SCG mechanism is dominant for a given material/temperature lenvironmental system, then the SCG parameters obtained, in principle at least, should be in a reasonable range of accuracy, regardless of test method. Furthermore, one must be able to predict life and/or strength from any loading history that could

\footnotetext{
- NASA Senior Resident Research Scientia, Glenn Research Center, Cleveland, OH 44135 (All correspondences to this address)
} 
be a combination of constant stress-rate/constant stress-rate, constant stress/constant stress-rate, or cyclic stress/constant stress-rate loading sequences. There have been some experimental attempts to evaluate the degree of crack growth or damage accumulation by determining "fast'-fracture "residual" strength of silicon nitride specimens that had been subjected to and then interrupted from tensile cyclic loading at elevated temperature [7]. However, in general, both analytical work and systematic experimental data on this subject rarely exist in the literature.

Consequently, the purpose of this work is to better understand how damage (SCG, creep or both) was accumulated with time for given loading history leading to failure of advanced structural ceramics at elevated temperatures. Numerical solutions of strength degradation in conjunction with crack growth were obtained for each loading history with a major assumption that the governing failure mechanism was slow crack growth Included in the test matrix were two typical methods of constant stress-rate ("dynamid fatigue") and constant stress ("static fatigue" or "stress rupture") tesling. The SCG and related parameters were determined on the basis of these test results. Then, a combination of two different loading sequences was applied to test specimens and the corresponding strengths were measured to see how strength degradation in the form of SCG/damage accumulation took place during the combined loading sequences. The combination of loading used in this testing included slow test rate/fast test rate (which is a combination of constant stress-rate/constant stress-rate testing, called here Case I loading history) and static loading/fast test rate (a combination of static stress/constant stress-rate testing, called Case II loading). The testing was interrupted after the first loading sequence at a specified time, and then the specimens were fractured at the second loading sequence using a fast test rate of typically $33 \mathrm{MPa} / \mathrm{s}$. The experimental results were compared with the numerical solutions.

\section{THEORETICAL BACKGROUND}

\section{Approach}

Numerical solutions of strength, crack size and other required variables for various loading histories are presented in this section. The schematic loading history considered in this study is depicted in Fig. 1. The first one, Fig. 1(a), called Case I loading, was a combination of two constant stress-rate testing with a fast test rate after a slow test rate. A specimen was subjected to a low stress rate. Then, the testing was interrupted at a specified time $J_{\text {int }}$ and resumed with a fast stress rate until the specinen fractured. The second loading history, Fig. 1(b), called Case $I$ loading, was a combination of constant stress and constant stress-rate testing. The testing was started initially with a constant stress, interrupted at a specified test time $J_{\text {int }}$ and then resumed by applying a fast stress rate until the specimen broke. The third laading history, Fig. 1(c), called Case III loading, which was a combination of cyclic stress and constant stress-rate testing, was simply a replacement of a static stress used in the Case II loading with cyclic stress. The ratio $(\varphi)$ of internuption time to time to failure is defined as follows:

$$
\varphi=\frac{J_{\text {int }}}{J_{f}}
$$

where $J_{i n}$ is the interruption time and $J_{f}$ is time to failure of a test specimen, subjected to only the first loading sequence (without the
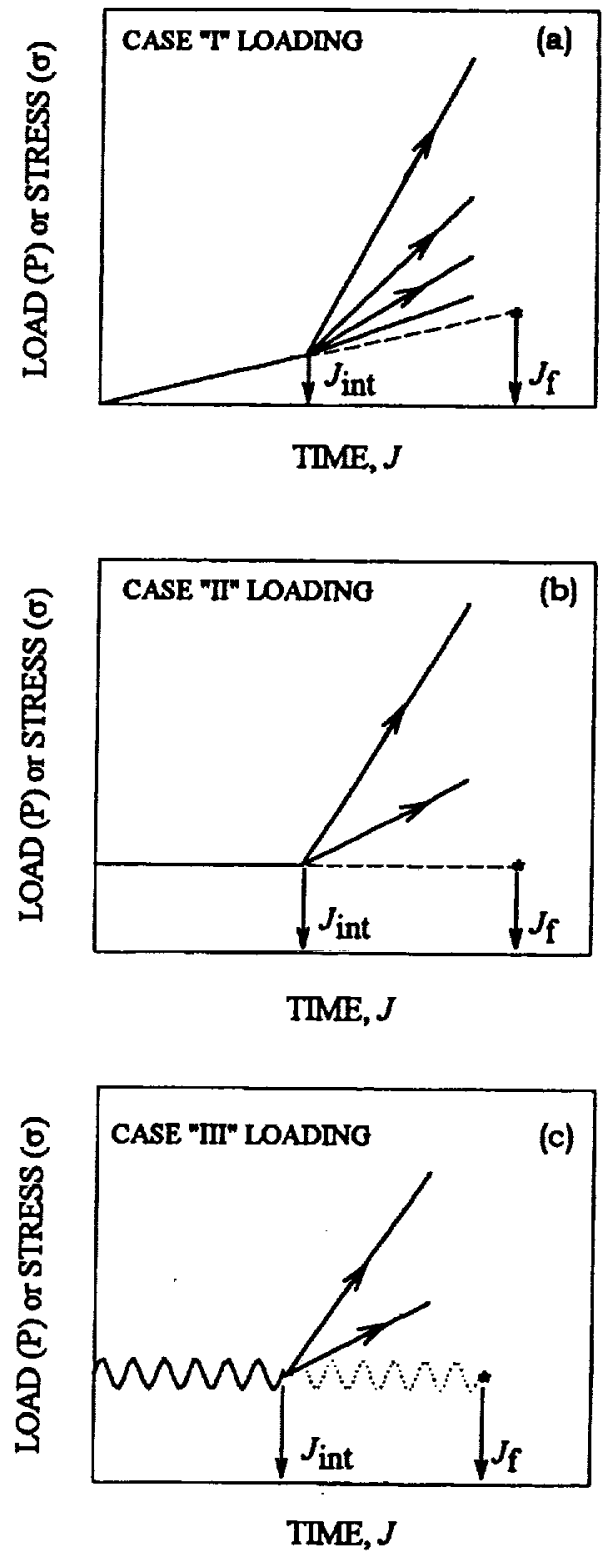

Fig. 1 Schematics of three loading historles considered: (a) Case I loading, (b) Case II loading and (c) Case III loading

second laading, i.e., $\varphi=1$ ) which is either constant stress-rate, constant stress or cyclic stress, sec Fig. 1. The case for $\varphi=0$ represents the second loading sequence with no the first laading sequence. The intemuption time was chosen such that the ratio ranged typically from $\varphi$ $=0$ to $90 \%$.

In many cases, slow crack growth of advanced ceramics under made I loading above the fatigue limit, either by stress corrosion at ambient temperature or by grain boundary sliding at elevated temperatures, can be expressed by the following empirical power-law relation [8] 


$$
v=\frac{d a}{d t}=A\left[\frac{K_{I}}{K_{I C}}\right]^{n}
$$

where $v, a, t$ are crack velocity, crack size, and time, respectively. $A$ and $n$ are the material/environment-dependent SCG parameters. $K_{1}$ is the mode I stress intensity factor (SIF), and $K_{\mathrm{IC}}$ is the critical SIF or fracture toughness of the material subjected to mode I loading. The simplistic analytical solutions of strength in constant stress-rate testing and of time-to-failure in constant stress and cyclic stress testing can be approximated as follows [9-11]:

$$
\begin{aligned}
\sigma_{f} & =D_{d}[\dot{\sigma}]^{1 / 1+n} \\
t_{f} & =D_{s}[\sigma]^{-n} \\
t_{f c} & =D_{c}\left[\sigma_{\max }\right]^{-n}
\end{aligned}
$$

where $\sigma_{f}$ is the fracture strength corresponding to the applied stress rate $(\dot{\sigma})$ in constant stress-rate testing, $t_{f s}$ is the time to failure subjected to a constant applied stress $(\sigma)$ in constant stress testing, and $t_{f}$ is the time to failure subjected to the maximum applied stress $\left(\sigma_{\max }\right)$ in cyclic stress testing. The parameters $D$ 's can be expressed as follows [9-11]:

$$
\begin{gathered}
D_{d}=\left[B(n+1) S_{i}^{n-2}\right]^{1 /(n+1)} \\
D_{s}=B S_{i}^{n-2} \\
D_{c}=\left(B S_{i}^{n-2}\right) /\left[\frac{1}{\tau} \int_{0}^{\delta}[f(t)]^{n} d t\right]
\end{gathered}
$$

where $S_{1}$ is the inert strength and $B=2 K_{1} d\left[A Y^{2}(n-2)\right]$ with $Y$ being the crack geometry factor in the relation of $K_{1}=Y \sigma a^{1 / 2}$. $f(t)$ is a periodic function in cyclic loading specified in $\sigma(t)=\sigma_{\max } f(t)$ with a range of 05 $f(t) \leq 1$, and $t$ is the period. The SCG parameters $n$ and $B$ (or $A$ ) can be obtained by a linear regression analysis with experimental data in conjunction with an appropriate equation, Eq. (3), (4) or (5), depending on the type of loading.

To obtain more generalized, convenient and accurate SCG analysis, several parameters that are commonly specified in the conventional analytical solutions (Eqs. 3 to 6 ) have to be minimized. This can be done by using a normalization scheme, as used in the previous studies $[12,13]$. The normalized variables utilized in the numerical approach were as follows $[13,14]$ :

$$
\begin{gathered}
K^{*}=\frac{K_{I}}{K_{I C}} ; J=\frac{A}{a_{A}} t ; C^{*}=\frac{a}{a_{A}} ; \sigma^{*}=\frac{\sigma}{S_{1}} ; \\
\sigma_{\max }^{*}=\frac{\sigma_{\max }}{S_{l}} ; \dot{\sigma}^{*}=\frac{\sigma^{*}}{J}
\end{gathered}
$$

where $K^{*}, J, C^{*}, \sigma^{*}, \sigma_{\max }^{*}$ and $\dot{\sigma}^{*}$ are, respectively, normalized stress intensity factor, normalized time, normalized crack size, normalized applied stress, normalized maximum applied stress (in cyclic loading) and normalized stress rate. $a_{f}$ is the critical crack size in the inert condition, or is the initial crack size. Using these variables, the crack propagation rate of Eq. (2) yields

$$
\frac{d C^{*}}{d J}=\left[K^{*}\right]^{n}
$$

The normalized SIF, $K^{*}$, in constant stress-rate and cyclic (sinusoidal) stress testing can also be expressed, respectively $[13,14]$

$$
\begin{gathered}
K^{*}=\dot{\sigma} * J\left[C^{*}\right]^{1 / 2} \\
K^{*}=\left\{\frac{1+R}{2}+\frac{1-R}{2} \sin \left[\left(\frac{\omega a_{A}}{A}\right) J\right\} \sigma_{\max }^{*}\left[C^{*}\right]^{1 / 2}\right.
\end{gathered}
$$

where $R$ is the stress (or load) ratio, defined as $R=\sigma_{\bmod } / \sigma_{\min }$ with $\sigma_{\min }$ being the minimum applied stress in cyclic loading, and $\omega$ is the angular velocity. The normalized SIF for constant stress loading is simply reduced to the case with both $R=1.0$ and $\sigma_{\max }^{*}=\sigma^{*}$ in Eq. (10).

The differential equation Eq. (8), together with Eqs. (9) and (10), was solved numerically using a fourth-order Runge-Kutta method for a given loading history. The initial condition was $C^{*}=1.0$ at $J=0$. The instability conditions were $K^{*}=1.0$ and $d K^{*} / d C^{*}>0$. The solution in cyclic loading was independent of frequency [14]; hence an arbitrary value of $\omega a_{f} / A=100$ was used in the analysis. At interruption time, $J_{\text {ints }}$ the corresponding variables including crack size, stress, stress intensity factor and time were provided to the next (second) loading sequence so that the required variables were determined until an instability condition was reached. Included in the typical input data were $n, R, \dot{\sigma}^{*}$ and $\sigma^{*}$ max. The major assumption in the analysis was that only one mechanism, i.e., slow crack growth, was associated with failure.

\section{Results of Numerical Solutions}

\section{Strength}

Normalized strength $\left(\sigma^{*}\right)$ as a function of percent of interruption time $\left(\varphi=J_{\text {ind }} / J_{\mathrm{f}}\right)$ for the Case I loading history is shown in Fig. 2. Six different values of $n$ ranging from $n=5$ to 160 were employed. For each $n$ value, the initial slow stress rate of $\dot{\sigma}^{*}=1 \times 10^{-5}$ was followed by the second loading which was chosen as $\dot{\sigma}^{*}=1 \times 10^{-4}, 1 \times 10^{-3}, 1 \times 10^{-2}$ and $1 \times 10^{-1}$. The choice of this range of $\dot{\sigma}^{*}$ was based on the typical range of applied stress rates commonly used in the actual constant stress-rate testing [1]. For the case of $n=5$ where SCG susceptibility is high, the strength degradation with respect to the strength at $\varphi=0$ depends on interruption time, particularly with increasing stress rate. The maximum strength degradation of about $16 \%$ and $10 \%$ occurred at $\varphi=90 \%$, respectively, for the highest stress rate of $\dot{\sigma}^{*}=1 \times 10^{-1}$ and for the lowest rate of $\dot{\sigma}^{*}=1 \times 10^{-4}$. This indicates that the initial loading up to $\phi=90 \%$ resulted in somewhat appreciable crack growth/damage-accumulation. For $n=10$, the maximum strength degradation was about $3 \%$ both at $\dot{\sigma}^{*}=1 \times 10^{-1}$ and $1 \times 10^{-4}$. For the case of higher resistance to SCG, $n \geq 20$, the strength degradation was negligible with less than $0.6 \%$ at $\phi=90 \%$, indicating that crack growth/damage-accumulation rarely occurred during the first loading sequence. Therefore, it is concluded that for $n \geq 20$ which is the case for most silicon nitrides and silicon carbides at elevated temperatures the first loading sequence would not have any significant influence on crack growth/damage, leading to negligible strength degradation. The second loading rate, which is at least one order of magnitude greater than the first one, controls exclusively the strength via crack growth. 

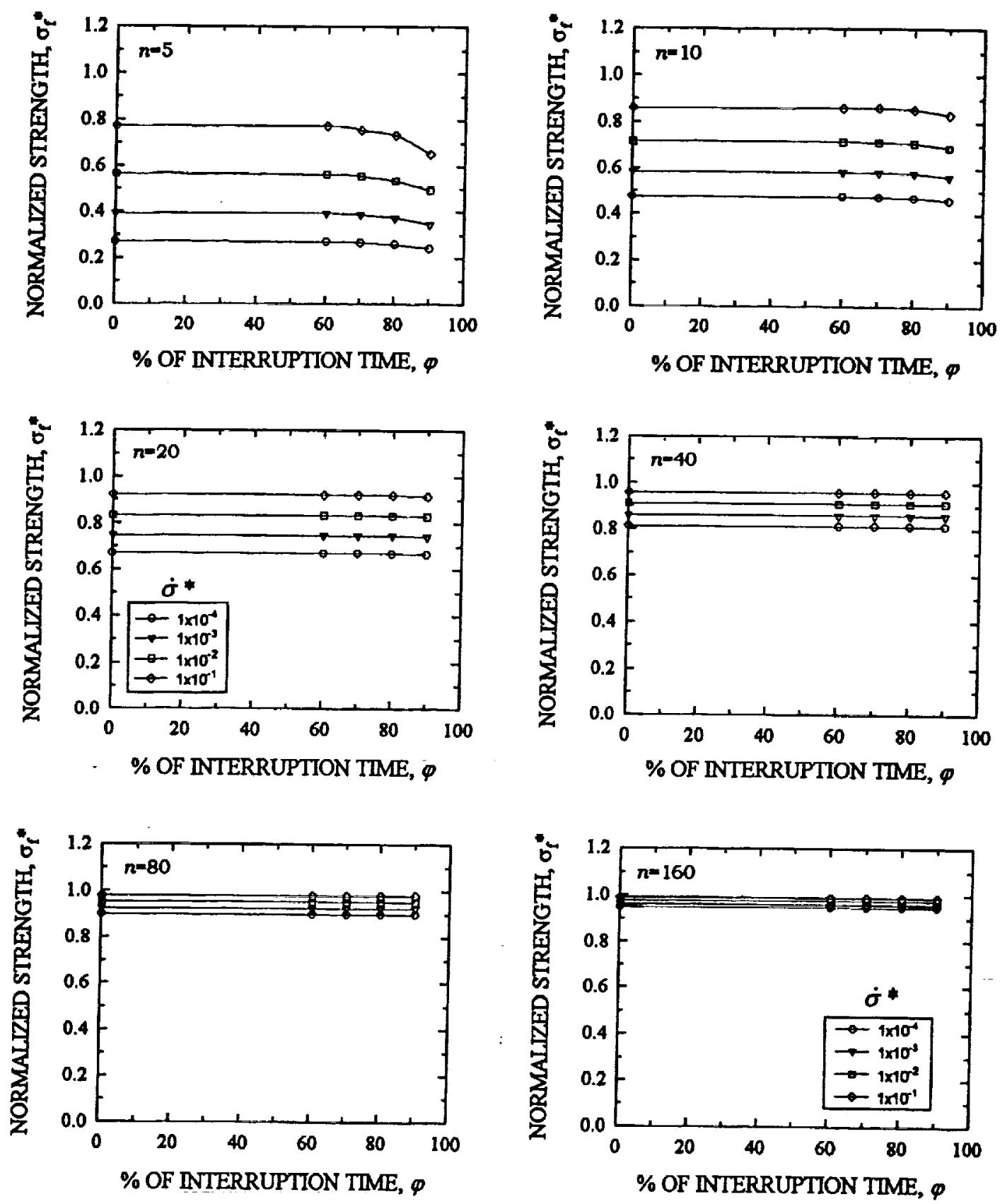

Fig. 2 Numerical results of normalized strength $\left(\sigma^{*}\right)$ as a function of percent of Interruption time $(\varphi)$ for different values of slow crack growth (SCG) parameter $n$ in Case I loading 
An analysis on how a crack grows under a given loading history will be presented in a later section.

The results of strength as a function of percent of interruption time $(=\varphi)$ for the Case II loading history, a combination of constant stress and constant stress-rate testing, Fig. $1(\mathrm{~b})$, is presented in Fig. 3. Two to three different normalized applied stresses, ranging from $\sigma^{*}=0.2$ to 0.95 depending on $n$ value, were used for each $n$ value. Since the susceptibility to SCG decreases with increasing $n$, higher applied stress with narrow range was employed for higher $n$ value. Two test rates of $\dot{\sigma}^{*}=1 \times 10^{-3}$ and $1 \times 10^{-1}$ were used in the second loading sequence. As in the Case I loading, for $n \leq 10$, strength degradation was significant to interruption time, particularly at both lower applied stress and higher stress rate of $\dot{\sigma} *=1 \times 10^{-1}$. For $n \geq 20$, strength degradation for a given value of $\phi$ was independent of either applied constant stress $\left(\sigma^{*}\right)$ or applied stress rate. However, the overall degree of strength degradation occurring for the whole range of $n$ 's was greater in the Case II loading than in Case I loading. For $n=5$, the maximum strength degradation of $42 \%$ occurred at $\Phi=90 \%$ with a loading combination of $\sigma^{*}=0.2$ and $\dot{\sigma} *=1 \times 10^{-1}$. For $n=10$, about 20 percent strength degradation was observed at $\varphi=90 \%$ for the combination of $\sigma^{*}=0.3$ and $\dot{\sigma}^{*}=$ $1 \times 10^{-1}$. For $n \geq 20$, the maximum strength degradation of $10 \%, 5 \%, 3$ $\%$ and $1 \%$ took place, independent of $\dot{\sigma}^{*}$, for $n=20,40,80$ and 160 , respectively. More dependency of strength degradation on interruption time $(\varphi)$, compared with the Case I laading, implies that the first, constant-stress loading sequence resulted in more crack growth/damage-accumulation, thus leading to lower strength when the damaged specimen was subjected to the second constant stress-rate loading sequence.

The results of strength as a function of interruption time $(\varphi)$ for the Case III loading, a combination of cyclic stress and constant stress-rate loading, see Fig. 1(c), is shown in Fig. 4. The second constant stressrate loading sequence was preceded by the first, sinusoidal cyclic stress with a R-ratio of $R=0.1$, until the specimen failed. Two to three different normalized maximum applied stresses, ranging from $\sigma_{\text {mex }}^{*}=$ 0.2 to 0.95 , were used for each $n$ value. Note that $\sigma^{*}$ ma applied in the Case III loading was identical in magnitude to $\sigma^{*}$ applied in the Case II loading. As in the case II loading, two stress rates of $\dot{\sigma}^{*}=1 \times 10^{-3}$ and $1 \times 10^{-1}$ were also used in the second loading sequence. Comparing the results in Figs. 3 and 4, it can be readily evident that for the given $n$ and $\sigma_{\max }^{*}=\sigma^{*}$ strength degradation in the Case III loading was almost the same as that in the Case II loading. It should be noted that constant stress (i.e., $R=1.0$ ) results in much longer life than cyclic stress with $R$ $=0.1[11,14]$. However, in terms of strength degradation as a function of percent of intermuption time, either constant stress (Case II loading) or cyclic stress (Case III loading) yielded the same result.

\section{Slow Crack Growth}

Typical examples of crack growth/damage-accumulation subjected to the three different loading histories are presented in Fig. 5 for both $n$ $=10$ and 20 . The figures show how an initial crack grows with time during the whole loading history until failure occurs. The loading combinations employed for each $n$ were as follows: $\dot{\sigma}^{*}=1 \times 10^{-5}$ $\left(1^{*}\right) \dot{\sigma}^{*}=1 \times 10^{-1}$ for Case I loading; $\sigma^{*}=0.5\left(1^{\text {at }} y \dot{\sigma}^{*}=1 \times 10^{-1}\left(2^{\text {nd }}\right)\right.$ for Case II loading, $\sigma^{*}=0.5\left(1^{x}\right) y \dot{\sigma}^{*}=1 \times 10^{-1}\left(2^{\text {nd }}\right)$ for Case III loading. Note again that the case of $\varphi=1.0$ represents only the first loading sequence applied a) For $n=10$ (Fig. 5A). For the Case I loading (Fig. 5A(a)), an initial crack subjected to only the first loading sequence of $\dot{\sigma} *=1 \times 10^{-5}$ (i.e., $\varphi=1.0$ ) remained almost unchanged in size for a long time, but started to grow very quickly at $J \geq 0.3848 \times 10^{5}$ until failure time of $J_{f}=$ $0.3849 \times 10^{5}$. This indicates that the initial crack startod to grow to instability at a time greater than $95 \%$ of failure time. Therefore, any interruption of loading below $\varphi=95 \%$ did not give any significant crack growth so that the resulting strength after the second loading sequence remained unchanged (compared with the strength at $\varphi=0$ ), irrespective of interruption time. This is also reflected as an insignificant strength degradation with respect to the strength at $\varphi=0$, as shown in Fig. 2 for $n=10$. Similar behavior as in the Case I loading was also observed in the Case II loading (see Figs. 5A(b)). Most major crack growth occurred close to and/or at failure time. However, during the first static loading sequence, an initial crack started to grow earlie and greater in size than that of the Case I loading. Hence, the resulting critical crack size after the second loading sequence of $\dot{\sigma}^{*}=1 \times 10^{-1}$ was increased with increasing interruption time $(\varphi)$. As a result, strength degradation as a function of $\varphi$ became much greater, compared with that of the Case I loading (see Fig. 3 for $n=10$ ). For the Case III loading, crack growth behavior in terms of interruption time was almost identical to that of the Case II loading, as can be seen by comparing Fig. SA(b) with Fig. SA(c). The only difference between Case II and III loading lied in time to failure: Time to failure for a given $n$ is always greater in cyclic $(R=0.1)$ than in constant stress $(R=1.0)$ loading $[11,14]$. Therefore, the resulting strength as a function of percent of interruption time $(\varphi)$ remained the same for either Case II (static) or Case III (cyclic) loading history, as shown in Figs. 2 and 3 for $n=10$.

b) For $n=20$ (Fig. 5B). For the case of $n=20$, the overall trend in crack growth behavior was very similar to the case of $n=10$. Note again that an initial crack started to grow close to and/or at failure time, independent of the type of loading history. However, because of higher resistance to SCG in case of $n=20$ the critical crack size at instability between $\phi=0$ and 0.9 was all smaller (and less dependant on interruption time) than that of the case for higher SCG susceptibility with $n=10$. As a consequence, strength degradation as a function of interruption time $(\varphi)$ was less significant compared with that of $n=10$ (see Figs. 2 through 4 for $n=20$ ).

Based on the numerical results on strength and crack growth, it can be summarized that strength degradation due to crack growth or damage accumulation as a result of the first loading sequence depends on interruption time $\varphi$ and SCG parameter $n$ for a given loading history. The strength degradation or degree of crack growth/damageaccumulation as a function of intermption time was significant for lower SCG parameters $n \leq 10$, but became insignificant with increasing SCG parameter of $n \geq 20$. This trend was observed more dominant for the Case I loading than the Case II or III loading history. The key factor that governs such strength degradation or crack growth behavior was that an initial crack started to grow typically close to and/or at failure time after a substantially long incubation time. This long incubation time, unique to ceramic materials exhibiting $n \geq 20$, was also a basis of the accelerating test methodology in constant stress-rate testing where depending on $n$ value appropriate preloading can be applied to test specimens prior to testing, thus saving a significant amount of test times [15]. 

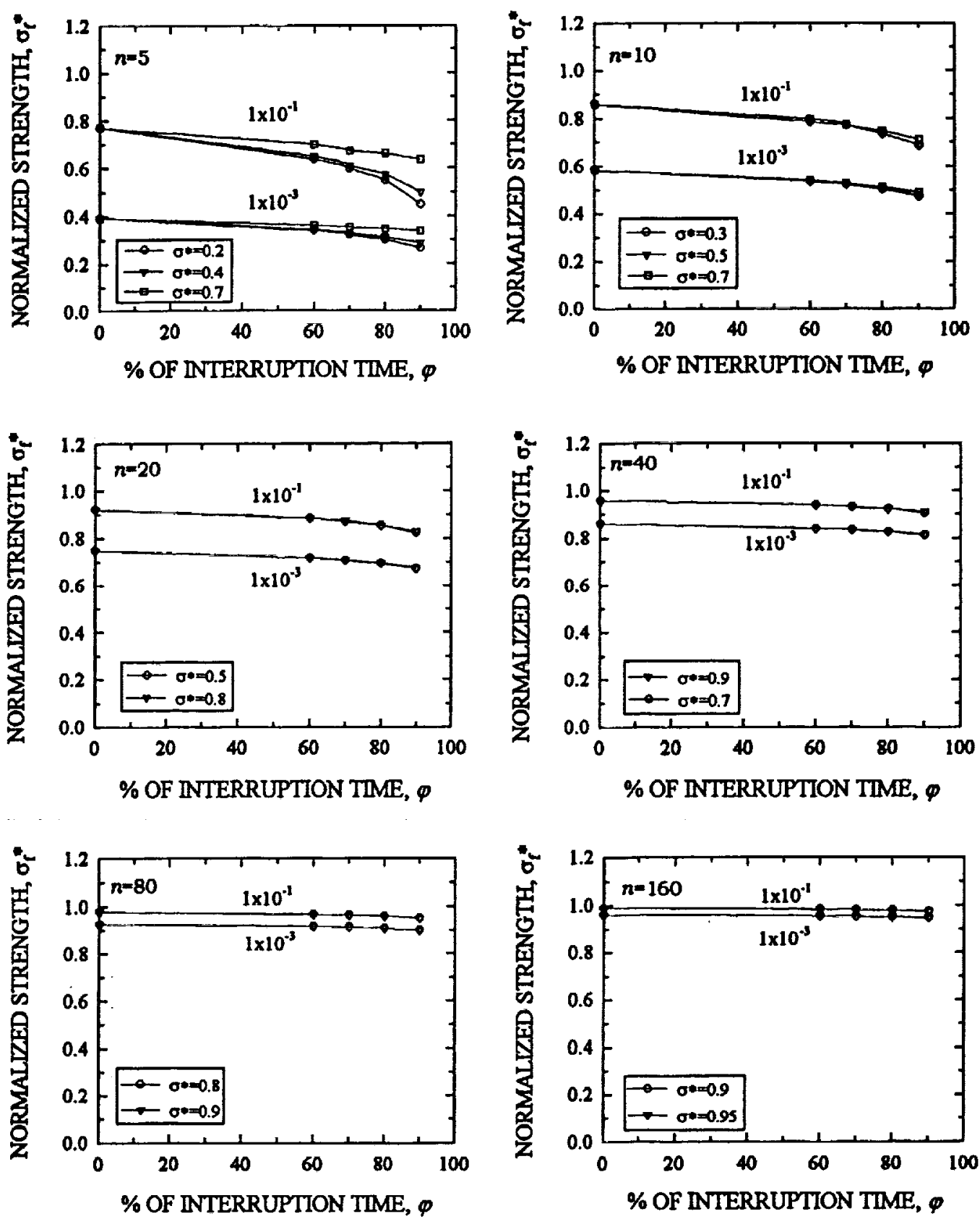

Fig. 3 Numerical results of normalized strength $\left(\sigma^{*}\right)$ as a function of percent of Interruption time $(\varphi)$ for different values of slow crack growth (SCO) parameter $n$ in Case II loading 

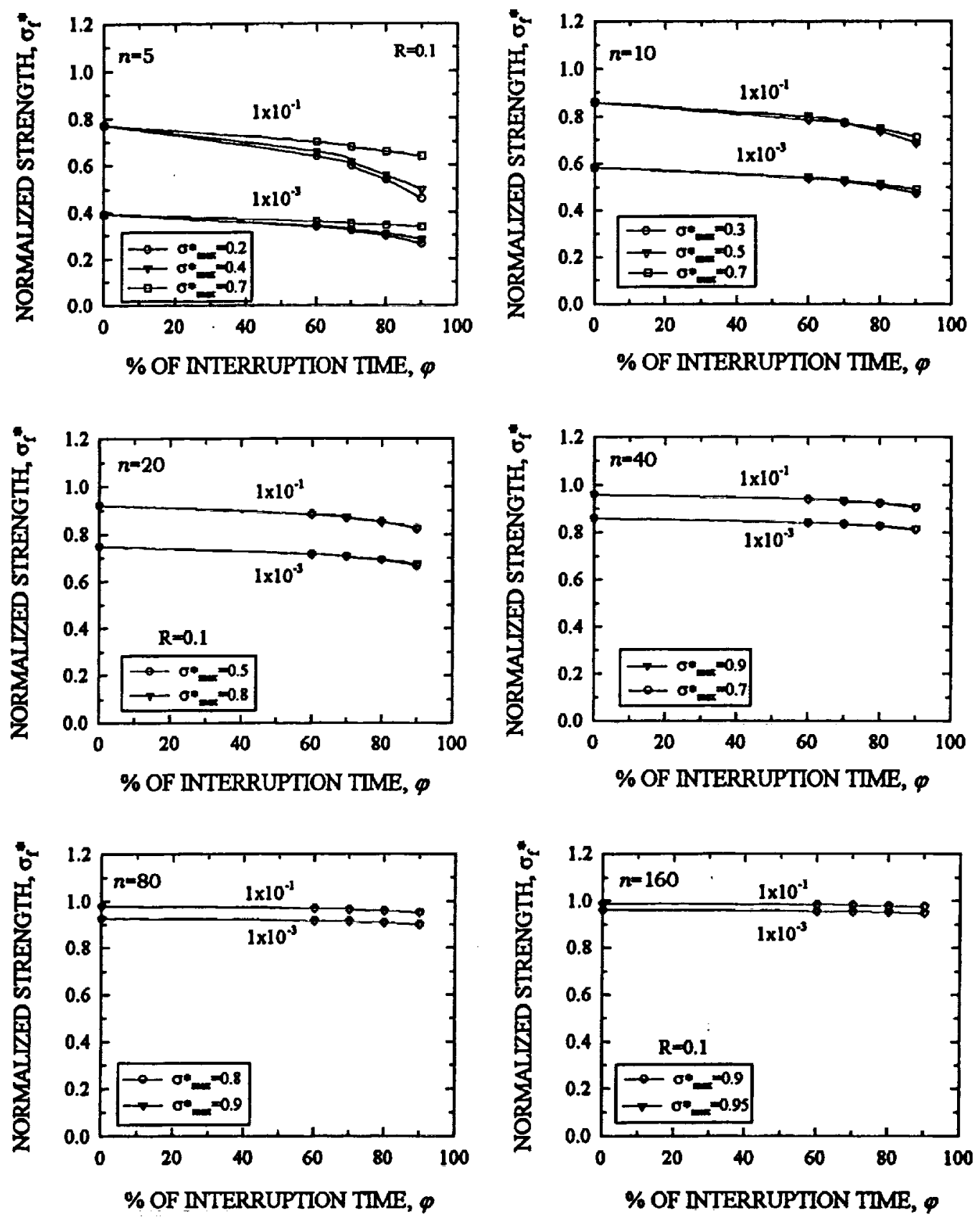

Fig. 4 Numerical results of normalized strength $\left(\sigma^{*} f\right)$ as a function of percent of interruption time $(\varphi)$ for different values of slow crack growth (SCG) parameter $n$ in Case III loading 

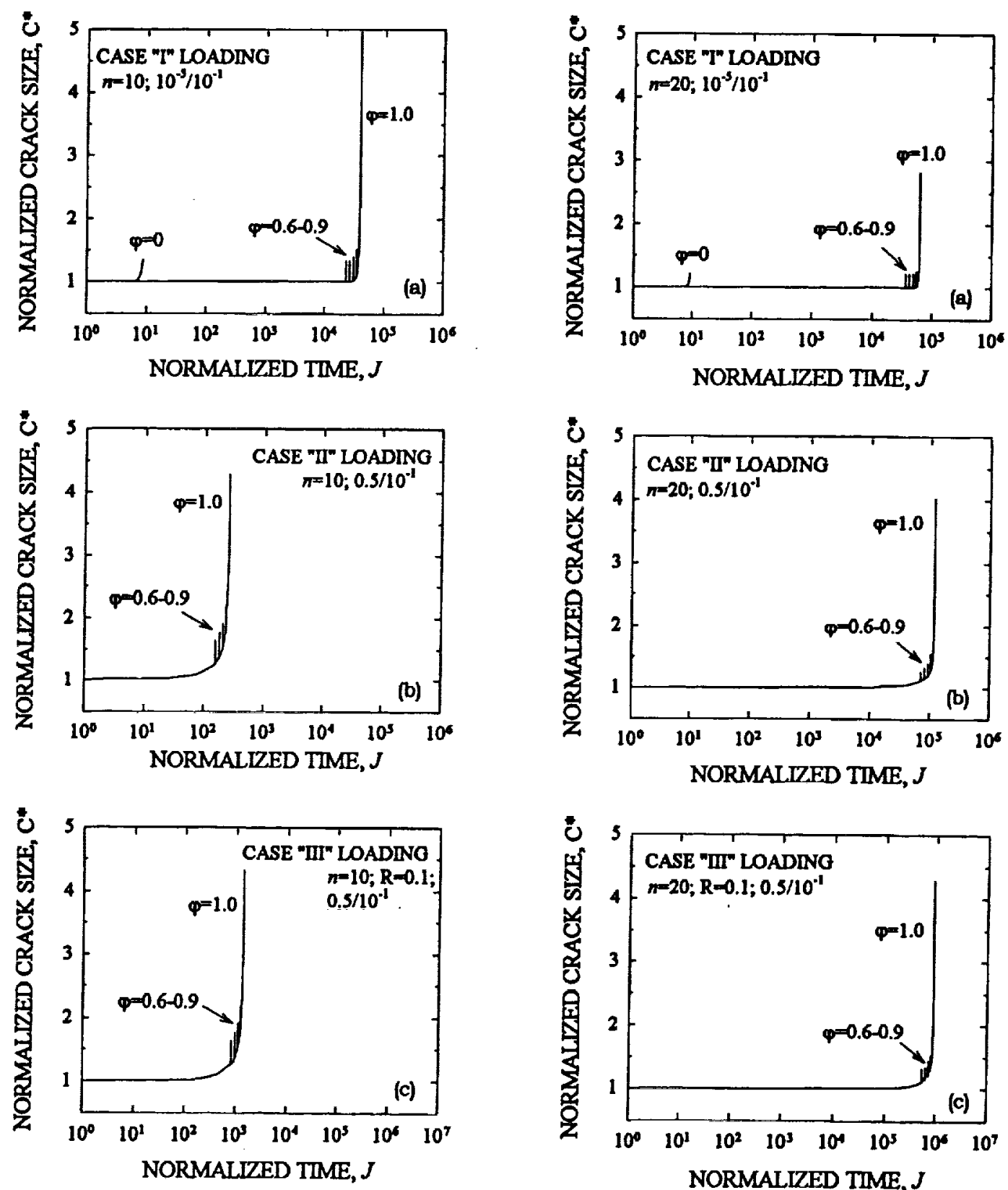

[A] $n=10$

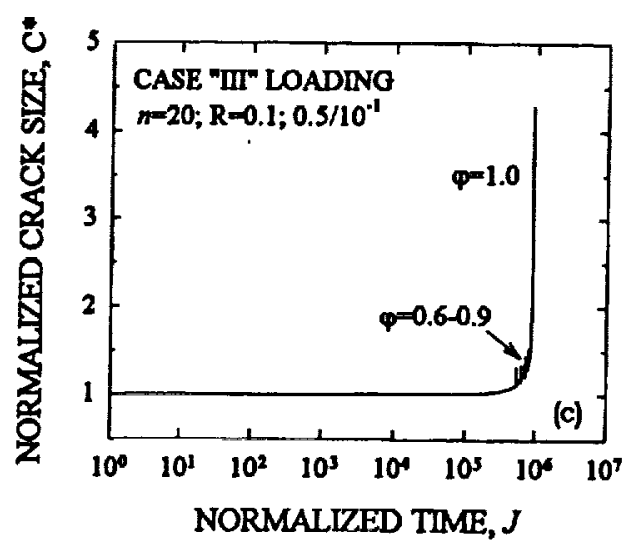

[B] $n=20$

Fig. 5 Numerical results of normalized crack size $\left(C^{*}\right)$ as a function of time $(\mathcal{H})$ for different values of interruption time $(\rho)$ in three loading historles: [A] For SCG parameter $n=10$; [B] For SCG parameter $n=20$ 


\section{EXPERIMENTAL PROCEDURE}

In order to verify the numerical solutions, experiments to cover different loading histories as specified in Fig.1, was conducted at elevated temperatures. The nominal dimensions of rectangular-beam test specimens in accordance with test method ASTM C-1211 [16] were $3 \mathrm{~mm}$ by $4 \mathrm{~mm}$ by $50 \mathrm{~mm}$, respectively, in height, width and length. Test specimens were subjected to appropriate flexural loading depending on the type of loading history using $\mathrm{SiC}$ four-point flexure fixtures with $20-\mathrm{mm}$ inner and $40-\mathrm{mm}$ outer spans via electromechanical and servo-hydraulic test frames (Instron Models 8562 and 8501). All test specimens were equilibrated at test temperatures for about 20 min prior to testing. Four different materials including 96 wt \% alumina, NC132 silicon nitride, AS800 silicon nitride, and Hexoloy silicon carbide were used in the Case I loading, while only 96 wt $\%$ alumina was used in the Case II loading. The reason for the choice of alumina in both Case I and II testing was that unlike other materials, $96 \mathrm{wt} \%$ alumina has exhibited a considerably small strength scatter with a Weibull modulus typically greater than 20 at either ambient and elevated temperatures [6]. Hence, it would be possible to see material's response to life and strength more clearly and accurately with even a small number (about 5 at each condition) of test specimens. Also note that the alumina was very susceptible to SCG at elevated temperatures $\geq 800^{\circ} \mathrm{C}$ with significantly low values of SCG parameter of $n=7-12$ [17], so that it would be much easier using the alumina to scrutinize the influence of SCG/damage-accumulation on the combined laading sequences more accurately. The experimental work for the Case III loading was not conducted in this study, primarily due to limited availability of test specimens.

\section{a) Caso I loading}

In the Case I load testing, the loading history included a slow test rate of $0.033 \mathrm{MPa} / \mathrm{s}$ for the first loading sequence and then a fast test rate of $33.33 \mathrm{MPa} / \mathrm{s}$ for the second loading sequence. The percentage of interruption time $\left(\varphi=t_{\min }(t)\right.$ ranged from $\varphi=70$ to $90 \%$. The average failure time $(=t)$ of test specimens only subjected to the first loading sequence (with $0.033 \mathrm{MPa} / \mathrm{s}$ ) was determined from the previous studies $[6,18]$, and used here as a reference value to calculate $t_{\text {nix }}$ for a given value of $\varphi$. Four ceramics including 96 wt \% alumina, NC132 silicon nitride, AS800 silicon nitride, and Hexoloy silicon carbide were tested at temperatures of $1000,1100,1200$ and $1371^{\circ} \mathrm{C}$, respectively. Typically a total of five specimens, depending on material, were used at each value of $\varphi$. The major mechanical and physical properties of the test materials such as Young's modulus, density, fracture toughness, strength and slow crack growth can be found elsewhere [18].

\section{b) Cese II looding}

Constant stress ("static fatigue") testing for 96 wt \% alumina was first conducted in flexure at $1000^{\circ} \mathrm{C}$ to determine SCG behavior and thus to obtain the time-to-failure data. Four different applied stresses ranging from 50 to $100 \mathrm{MPa}$ were employed, with a total of five to nine specimens tested at each applied stress. The Case II loading history consisted of a constant stress (for the first loading sequence) and a fast stress rate of $33.33 \mathrm{MPa} / \mathrm{s}$ (for the second sequence). Two applied stresses of 50 and $65 \mathrm{MPa}$ were used in the first loading sequence. Three different values of interruption time, $\varphi=60,75$ and $90 \%$, were utilized at each applied stress, with a total three to five specimens tested at each interruption time.

\section{EXPERIMENTAL RESULTS AND DISCUSSION}

\section{(a) Case / Loading}

The results for the Case I loading tests for $96 \mathrm{wt} \%$ aluming, NC132 silicon nitride, AS800 silicon nitride and Hexoloy silicon carbide are summarized in Fig. 6. The figure included flexure strength as a function of percent of interuption time $\boldsymbol{\varphi}$ for each material. The horizontal line represents the strength determined with zero interruption time $\varphi=0$, that is, the 'fast'-fracture strength evaluated at $33.33 \mathrm{MPa} / \mathrm{s}$ $[6,18]$. The three materials including $\mathrm{NC1} 32$ and AS800 silicon nitrides and Hexoloy silicon carbide exhibited a somewhat appreciable variation (in average sense) in strength between $\varphi=0$ and $\varphi=80$ or 90 $\%$. It is believed that this was attributed to the inherently large strength scatter, typical of advanced ceramics that ranges commonly from 10 to 13 in Weibull modulus. By contrast, 96 wt \% alumina exhibited a very small scatter, thus readily concluding that the difference in strength between $\varphi=0$ and $\varphi=80$ or $90 \%$ was insignificant.

\section{(b) Case I/ Loading}

Figure 7 shows the results of constant stress testing for 96 wt \% alumina at $1000^{\circ} \mathrm{C}$. The slow crack growth parameters $n$ and $D_{b}$ in Eq. (4) were determined as $n=9.8$ and $D_{8}=4.69 \times 10^{20}$ with units of ' $\mathrm{MPa}$ ' in stress and 'second' in time. Note that SCG parameter $n$ determined from constant stress testing was in reasonable agreement with $n=8.3$ from constant stress-rate testing determined from a previous study [6]. The results of the Case II loading tests was presented in Fig. 8, where strengths determined at $33.33 \mathrm{MPa} / \mathrm{s}$, after the first laading sequence of constant stress of 50 or $65 \mathrm{MPa}$, was plotted as a function of percent of interruption time $(\varphi)$. As scen in the figure, the strength exhibited a significant scatter particularly at $\phi=75$ and $90 \%$, much greater than that exhibited in the Case I loading history for the same alumina material. It is believed that this was attributed to the fact that no exact failure time of each individual test specimen subjected to the Case II loading could be known and that as a result the actual corresponding interruption time for each test specimen could not be determined. This will be discussed in a later section.

\section{(c) Comparison of Experimental Data with Numerical Solutions}

The comparison of strength as a function of $\varphi$ between the experimental data and the numerical solutions for each loading history was made and presented in Figs. 9 and 10. The reduced strength $\left(\sigma_{r}{ }^{*}\right)$ used here was defined such that strength determined at any given value of $\varphi$ was normalized with respect to the strength determined at $\varphi=0$, which is expressed as follows:

$$
\sigma_{r} * \frac{\sigma_{p}}{\sigma_{p=0}}
$$

where $\sigma_{\varphi}$ is the strength at any given value of $\varphi$ (which is determined at a fast test rate of $33.33 \mathrm{MPa} / \mathrm{s}$ after the first loading sequence) and $\sigma_{\varphi=0}$ is the strength determined at $\phi=0$ (which is simply the 'fast'fracture strength determined at $33.33 \mathrm{MPa} / \mathrm{s}$ without any first loading sequence).

i) Case / loading. As seen in Fig. 9, except for 96 wt \% alumina, the discrepancy between the experimental mean-strength data and the numerical solutions was somewhat large. However, as aforementioned, considering low Weibull modulus (10-13) typical of many advanced 

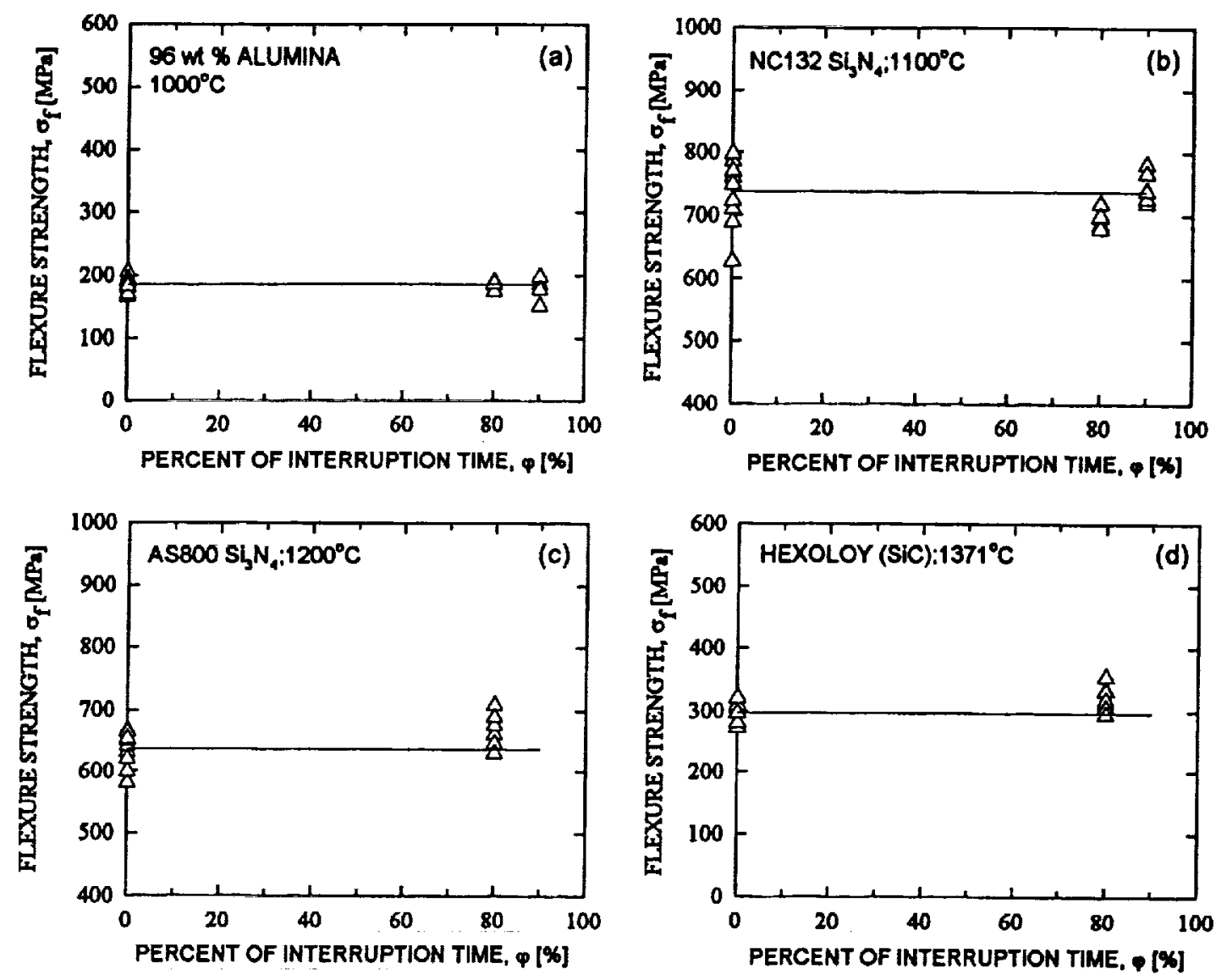

Fig. 6 Experimental results of flexural strength as a function of percent of interruption time $(\varphi)$ for Cace I loading tests, determined from 96 wt \% alumina, NC132 and AS800 silicon nitrides, and Hexoloy silicon carbide at elevated temperatures. Each solld line represents the mean strength at $\varphi=0$.

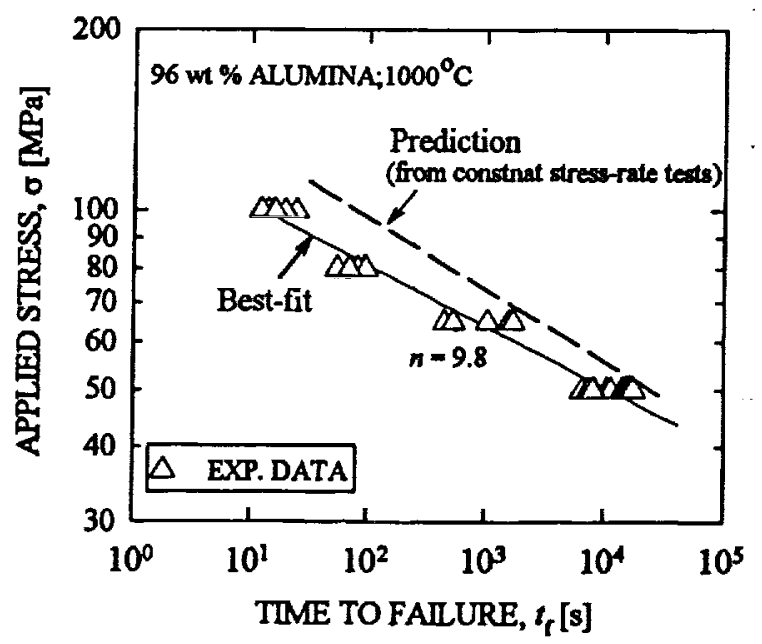

Flg. 7 Experimental results of constant stress ("static fatigue") testing for 96 wt $\%$ alumina at $1000^{\circ} \mathrm{C}$. A prediction made from the constant stress-rate ("dynamic fatlgue") testing data [6] was Included as a dotted line. 


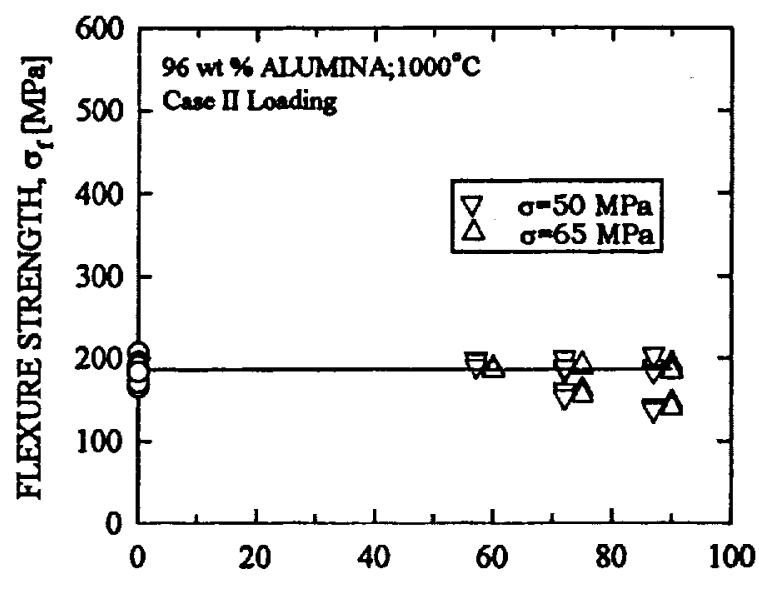

PERCENT OF INTERRUPTION TIME, $\varphi[\%]$

Fig. 8 Experimental results of flexure strength as a function of percent of interruption time $(\varphi)$ for Case II loading tests, determined from 96 wt \% alumina at $1000^{\circ} \mathrm{C}$. Two different constant stresses of 50 and $60 \mathrm{MPa}$ were employed. The solid line represents the mean strength at $\varphi=0$.
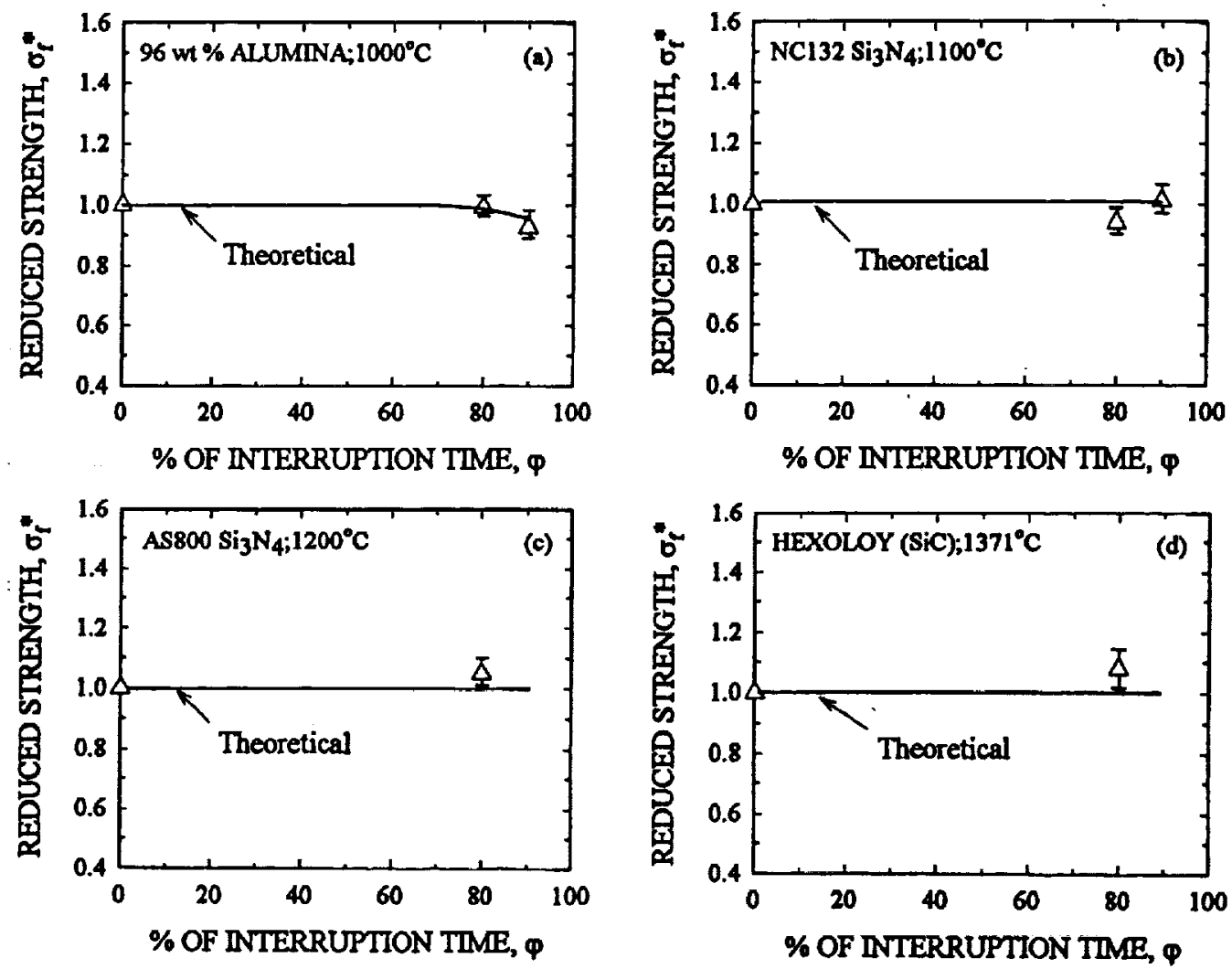

Fig. 9 Comparison of experimental data with numerical solutions ("theoretical") in Case I loading: (a) 96 wt \% alumina, (b) NC132 silicon nitride, (c) AS800 silicon nitride, and (d) Hexoloy silicon carbide. Error bars represents \pm 1.0 standard deviation, nomalized with respect to a mean strength at $\phi=0$. 
ceramics including the test materials (except 96 wt \% alumina), the discrepancy is believed rather statistically insignificant The experimental data for $96 \mathrm{wt} \%$ alumina which exhibited a considerably small strength scatter were in good agreement with the theoretical prediction. Based on the results shown in Fig. 9, several conclusions were made. First, the governing mechanism associated with failure for these test materials was slow crack growth. Some materials such as alumina and $\mathrm{NCl} 32$ silicon nitride exhibited some degree of creep deformation ( $\leq 0.2 \%$ creep strain) at a lower test rate of $0.033 \mathrm{MPa} / \mathrm{s}$. Despite such creep mechanism presented, the agreement between experimental data and prediction was still reasonable, implying SCG to be a dominant failure mechanism. Second, the phenomenon typical of advanced ceramics, which showed numerically that for $n \geq 10$ in constant stress-rate condition an initial crack started to grow at and/or close to failure time after a long incubation time, was verified. This was verified from the results that percent of interruption time up to $\varphi=$ $90 \%$ did not show any significant crack growth or damage accumulation, as reflected in insignificant strength degradation. This 'long-incubation' phenomenon was also validated previously by the accelerating test technique developed in constant stress-rate testing [15]. Finally, the slow crack growth formulation of Eq. (2) well described the actual SCG behavior of the test materials at elevated temperatures. Note that the numerical solution was made exclusively based on such SCG formulation so that if poor agreement would exist, then it would be indicative of inapplicability of the SCG formulation to the actual material behavior.

ii) Case // loading. The reduced strength as a function of percent of interuption time $(\varphi)$ for 96 wt \% alumina is presented in Fig. 10. Unlike the Case I loading history (Fig. 9), the difference between the experimental mean-strength data (with 'triangle' symbols) and the theoretical prediction was amplified even for the same alumina material. The reason for this discrepancy can be reasoned as follows. Because of the two combined loading sequences, no exact failure time of each individual test specimen exclusively subjected to the first loading sequence (constant stress) could be known so that the actual interruption time for each test specimen can never be determined. Note that the (nominal) time-to-failure at each applied stress was taken as an average failure time determined from the specimens subjected to 50 $\mathrm{MPa}$ or $65 \mathrm{MPa}$. The corresponding interruption time was calculated simply from a relation of $t_{\text {int }}=\varphi t_{f}$ for a given value of $\varphi$. Furthermore, as seen in Fig. 7, the scatter in time to failure was greater than that of strength typically observed in constant stress-rate testing [6], thus further increasing the uncertainty in failure time. Therefore, some specimens would have been actually subjected to greater interruption time than the nominal interruption time, while other specimens to less interruption time. As a consequence, this would have resulted in difference in SCG/damage-accumulation even with the same nominal $\varphi$, thereby resulting in a wide scatter in strength. The discrepancy would be small if the strength at lower end of data points, which would be close to the actual failure-time data, was used, as shown in the figure with the 'circle' symbol. Certainly, the discrepancy will be diminished if a large number of test specimens are used.

\section{(d) Comparison of SCG Behevior between Constant Stress-Rate and Constant Stross Testing}

As stated before, the SCG parameter $n$ for 96 wt \% alumina was in reasonable agreement between constant stress-rate and constant stress testing with the respective values of $n=8.3$ and 9.8. It is possible to onvert the SCG data from one test method to another by using the

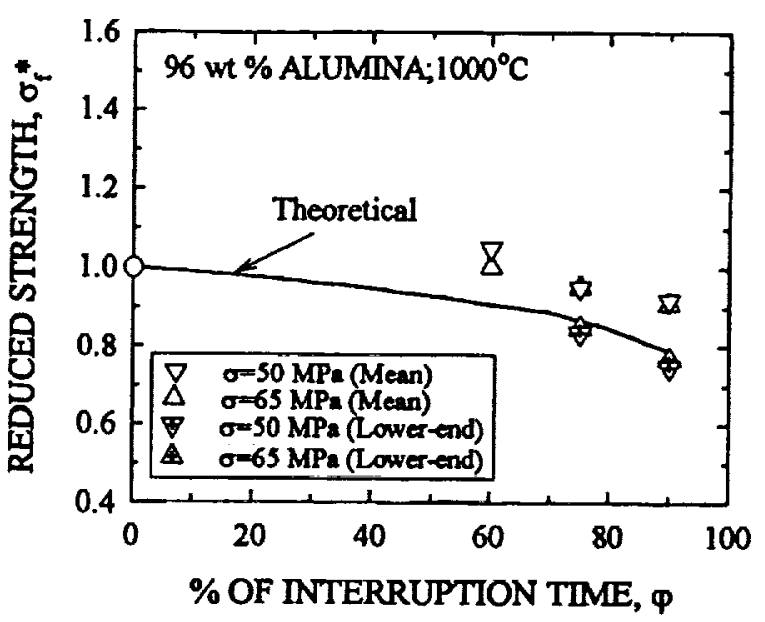

Fig. 10 Comparison of experimental data with numerical solutions ("theoretical") in Case II loading teots for 96 wt \% alumina at $1000^{\circ} \mathrm{C}$. Each data point with triangle' symbol represents an overall mean strength value (normalized). The data points with 'triangle's' symbols (inner crossmarked) represent the lower-end strength values (normallized) from the data In Fig. 8. Error bars were omitted from plots for clarity.

appropriate relations shown in Eqs. (3) to (6). The resulting comparison is depicted in Fig. 7, where the prediction from constant stress-rate ("dynamic fatigue") [6] to constant stress ("static fatigue") testing was included as a dotted line. Considering the inherent scatter in time to failure, reasonable agreement was found between the two data, implying that the mechanism associated with failure for both cases was presumably slow crack growth. It was observed that creep deformation in constant stress testing was much greater than that in constant stress-rate testing, since test time was much longer in constant stress testing. A maximum creep strain of about $0.4 \%$ was found for the test specimens subjected to an applied stress of $50 \mathrm{MPa}$. In spite of such appreciable creep deformation, overall agreement between the two test methods was reasonable, again indicative of SCG as an operative failure mechanism involved in both constant stress-rate and constant stress testing for this material system. However, some effect by creep deformation, particularly in constant stress ("static fatigue"), should not be overlooked, since some stress redistribution would be expected for test specimens subjected to long-term, constant stress testing. This creep effect, of course, becomes more dominant at higher temperatures, resulting in more deviation between the two test methods.

Since the predictions of strength were in reasonable agreement with experimental data, independent of the type of loading history or the type of testing, it is concluded that slow crack growth was a unique mechanism associated with failure for $96 \mathrm{wt} \%$ alumina as well as for other test materials. Therefore, it is feasible in principle using the numerical analysis developed in this work to predict life and/or strength degradation for any given simple or complex loading history as long as an explicit mathematical expression of load history can be made. More importantly, the analysis can be used in conjunction with appropriate experiments -using one of three loading histories- to promptly assess a 
governing failure mechanism involved in the conventional lifeprediction testing, which could be either constant stress-rate, constant stress, or cyclic stress testing. Furthermore, the analysis would be possible to be used at least as a quantitative tool for damage assessment by estimating/predicting crack growth/damage-accumulation of a structural component in service. A verification rin for the numerical analysis for the Case III loading history was not made in this work, so it will be a subject of future study.

\section{CONCLUSIONS}

1) For $n \leq 10$, simulated strength degradation as a function of percent of intemuption time was significant for all the Case I, II and III loading histories. For the given interruption time $\varphi$ and $n$, the degradation was greater in constant or cyclic stress (Case II or III) than in constant stress-rate laading (Case I). By contrast, for $n \geq 20$, the degradation became negligible either for the Case I, II or III loading history.

2) The numerical solutions of strength degradation were examined using the experimental data determined at elevated temperatures from four different advanced ceramics -two silicon nitrides, one silicon carbide and one alumina- for the Case I loading history, and from alumina for the Case II loading. The experimental data was in reasonable agreement with the numerical solutions for both loading histories. Also the phenomenon typical of advanced ceramics, which has shown that in constant stress-rate condition an initial crack starts to grow at and/or close to failure time after a long incubation time, was verified

3) The numerical analysis that assumed slow crack growth as a governing failure mechanism was in good agreement with the experimental data. Despite some degree of creep deformation presented, slow crack growth was presumably a significantly operating failure mechanism involved in all the test materials, regardless of type of loading history or type of test method. Notwithstanding some deviation, there was also reasonable agreement in SCG behavior between constant stress-rate testing and constant stress testing for $96 \mathrm{wt}$ $\%$ alumina. This supports that the widely utilized SCG formulation of $v=A\left[K_{1} / K_{K}\right]^{n}$ described reasonably the slow crack growth behavior of the test materials.

4) It appears that the analysis in conjunction with proper experiments, using one of three loading histories (Case I preferred), may be utilized as a tool for damage (SCG and creep) assessment of test specimens subjected to conventional life prediction testing. However, care must be exercised when several failure mechanisms such as SCG, creep and oxidation are actively operating in series at higher temperatures. A convenient analytical tool(s) accessible to such combined conditions, currently not available though, is inevitable.

\section{Acknowledgements}

The authors are thankful to R. Pawlik of NASA Glenn for the experimental work. This work was sponsored in part by the HITEMP project, NASA Glenn Research Center, Cleveland, OH.

\section{REFERENCES}

1. "Standard Test Method for Determination of Slow Crack Growth Parameters of Advanced Ceramics Using Constant Stress-Rate Flexural Testing at Ambient Temperature," ASTM C1368-97, Anmual Book of ASTM Standands Vol. 15.01, American Society for Testing and Materials, Philadelphia, PA (1998).

2. "Standard Test Method for Determination of Slow Crack Growth Parameters of Advanced Ceramics Using Constant Flexural Stress-Rate Testing at Elevated Temperatures," in ballot process under ASTM C28 Advanced Ceramics Committee, American Society for Testing and Materials, Philadelphia, PA (1999).

3. G. D. Quinn and R. Morrell, "Design Data for Engincering Ceramics: A Review of the Flexure Test," J. Am. Ceram. Sac., Vol. 74, 1991, pp. 2037-2066.

4. T. Fett and D. Munz, "Determination of Crack Growth Parameter $\mathrm{N}$ in Ceramics under Creep Condition," $J$. Testing \& Evaluation, Vol. 13, 1985, pp. 143-151.

5. O. M. Jadaan, "Life Prediction for Ceramic Tubular Components," in Life Prediction Methodologies and Data for Ceramic Materials, ASTM STP 1201, Edited by C. R. Brinkman and S. D. Duffy, American Society for Testing and Materials, Philadelphia, 1991, pp. 309-332.

6. S. R. Choi and J. P. Gyekenyesi, "Some Limitations in the Elevated-Temperature, Constant Stress-Rate Flexural Testing for Advanced Ceramics with Reference to the New, AmbientTemperature Test Standard ASTM C1368," Ceram. Eng. Sci. Proc., Vol. 19, 1998, pp. 595-605.

7. L. Chuck, D. E. McCullum, N. L. Hecht, and S. M. Goodrich, "High Temperature Tension-Tension Cyclic Fatigue for a Hipped Silicon Nitride," Ceram. Eng. Scl. Proc., Vol. 12, 1991, pp. 1509-1523.

8. S. M Wiederhom, "Subcritical Crack Growth in Ceramics," in Fracture Mechanics of Cenamics, Vol. 2, Edited by R. C. Bradt, D. P. H. Hasselmann, and F. F. Lange, Plenum Press, New York, 1974, pp. 613-646.

9. J. E. Ritter, "Engineering Design and Fatigue Failure of Brittle Materials," in Fracture Mechanics of Ceramics, Vol. 4, Edited by R. C. Bradt, D. P. H. Hasselmann, and F. F. Lange, Plenum Press, New York, 1978, pp. 661-686.

10. A. G. Evans, "Slow Crack Growth in Brittle Materials under Dynamic Loading Conditions," Int. J. Fracture, Vol. 10, 1974, pp. 1699-1705.

11. A. G. Evans and E. R. Fuller, "Crack Propagation in Ceramic Materials under Cyclic Loading Conditions," Metall. Trans., Vol. 5, 1974, pp. 27-33.

12. B. R. Lawn, D. B. Marshall, G. R. Anstis and T. P. Dabbs, "Fatigue Analysis of Brittle Materials Using Indentation Flaws, Part 1. General Theory," J. Mater. Sci., Vol. 16, 1981, pp. 2846-2854.

13. S. R Choi, J. E. Ritter and K. Jakus, "Failure of Glass with Subthreshold Flaws," J. Am. Ceram. Sac., Vol. 72, 1990, pp. 268-274. 
14. S. R. Choi and J. A. Salem, "Cyclic Fatigue of Brittle Materials with an Indentation-Induced Flaw System," Mat. Sci. Eng., Vol. A208, 1996, pp. 126-130.

15. (a) S. R. Choi and J. P. Gyekenyesi, "Fatigue Strength as a Function of Preloading in Dynamic Fatigue Testing of Glass and Ceramics" ASMIE J. Eng. Gas Turbines \& Power, Vol. 119, 1997, pp. 493-499. (b) S. R. Choi and J. A. Salem, "Preloading Technique in Dynamic Fatigue Testing of Glass and Ceramics with an Indentation Flaw System," J. Am. Cenam. Soc., Vol. 79, 1996, pp. 1228-1232.

16. "Standard Test Method for Flexural Strength of Advanced Ceramics at Elevated Temperatures," ASTM C1211-98a, Annual Book of ASTM Standands Vol. 15.01, American Society for Testing and Materials, Philadelphia, PA (1998).

17. S. R. Choi and J. A. Salem, "'Untra'-Fast Fracture Strength of Advanced Ceramics at Elevated Temperatures," Mat. Sci. Eng., Vol. A242, 1998, pp. 129-136.

18. S. R Choi and J. P. Gyekenyesi, "UItra'-Fast Fracture Strength of Advanced Structural Ceramics at Elevated Temperatures: An Approach to High-Temperature 'Inert' Strength" Presented at the $7^{\text {th }}$ Fracture Mechanics of Ceramics Symposium, July 20-23, 1999, Moscow, Russia; To be published in Fracture Mechanics of Ceramics, Plenum Publishing Corp. (2000). 